\title{
Depression, Anxiety and Stress in Adult Children Caregivers of Oncological Patients
}

\author{
Chapter $\cdot$ November 2018
}

DOI: 10.29290/AMHS.1.1.2018.1-25

\section{CITATIONS}

\section{5 authors, including:}

Ricardo João Teixeira

REACH

51 PUBLICATIONS 212 CITATIONS

SEE PROFILE

Gabriela Ferreira

University of Minho, School of Psychology, Psychology Research Centre 33 PUBLICATIONS 142 CITATIONS

SEE PROFILE
203

Marta Pereira

University of Minho

15 PUBLICATIONS 35 CITATIONS

SEE PROFILE

M. Graça Pereira

263 PUBLICATIONS 1,600 CITATIONS

SEE PROFILE

Some of the authors of this publication are also working on these related projects:

mindfulness, emotion regulation, alexithymia, experiential avoidance, cognitive rumination, grief, cancer caregivers View project

I. Investigação Determinants of women's health (estudo inicial finalizado em 2014 com 767 mulheres; estudo em curso nos cuidados de saúde primários - ARS Norte): avaliação dos conhecimentos, atitudes e comportamentos de risco nas mulheres portuguesas, utentes da consulta de planeamento familiar e preditores de

comportamentos de risco; Revitimização, perda de recursos e perturbação pós-stress traumático; Impacto do abuso físico, sexual e emocional na infância, no bemestar psicológico e no comportamento de risco; Stress, recursos psicossociais e sintomatologia depressiva. View project 


\title{
Chapter 01
}

\section{Depression, Anxiety and Stress in Adult Children Caregivers of Oncological Patients}

\author{
Ricardo João Teixeira ${ }^{1,2,3^{*}}$, Marta Pereira ${ }^{1,}$ Sara Faria ${ }^{1,}$ Gabriela Ferreira ${ }^{1}$ \\ and M Graça Pereira ${ }^{1}$ \\ ${ }^{1}$ University of Minho, School of Psychology, Portugal \\ ${ }^{2}$ Clínica da Ordem, Psychology Department, Portugal \\ ${ }^{3}$ CESPU, Institute of Research and Advanced Training in Health Sciences \\ and Technologies, Portugal
}

*Corresponding Author: Ricardo João Teixeira, University of Minho, School of Psychology, Braga, Portugal, Email: ricardojft@gmail.com

First Published August 13, 2018

Copyright: @ 2018 Ricardo João Teixeira, et al.

This article is distributed under the terms of the Creative Commons Attribution 4.0 International License

(http://creativecommons.org/licenses/by/4.0/), which permits unrestricted use, distribution, and reproduction in any medium, provided you give appropriate credit to the original author(s) and the source. 
Advances in Mental Health Studies

\begin{abstract}
The aim of this study is to describe levels of depression, anxiety, and stress in adult offspring of cancer patients; and to analyze gender differences in psychological morbidity, as well as the association between psychological morbidity and traumatic symptomatology. This study is correlational with a sample of 214 adult offspring who completed the Depression, Anxiety and Stress Scales (DASS-21) and the Impact of Event Scale-Revised (IES-R). The results revealed that 6-60\% of the participants showed 'normal' or 'mild' levels of stress, anxiety, or depression; $15-26 \%$ 'moderate' levels; and 4-12\% 'severe' or 'extremely severe' levels. Women had higher levels of anxiety and stress than men. Positive correlations were found between the DASS21 and the IES-R. In conclusion, some adult offspring caregivers reveal severe levels of psychological morbidity. The results show a need for psychological intervention in this population, particularly in the female gender.
\end{abstract}

\title{
Introduction
}

There is a growing recognition that the diagnosis and treatment of cancer not only causes significant discomfort to patients but also to their families. Increasingly, family members are becoming the leading providers of informal care for cancer patients [1,2], and some researchers have thus begun to see family members as 'co-sufferers' in the fight against this disease [3]. Studies have shown that the diagnosis of cancer very often causes distress in patients and informal caregivers, in the forms of depression, severe levels of anxiety and stress $[4,5]$. The aim of this chapter is to describe levels of depression, anxiety, and stress, to analyze gender differences in psychological morbidity, as well as the association between psychological morbidity and traumatic symptomatology in adult offspring of cancer patients.

www.avidscience.com 
Advances in Mental Health Studies

\section{Psychological Distress in Adult Offspring Car- egivers of Oncological Patients}

Cancer occurs in the context of a family system, producing negative effects on the functioning of the system and on each of its elements. Considering that, in a system, the behavior of each of its members is inseparable from the behavior of the others; there is a circularity in the relationship between patient and family [6,7]. The diagnosis of cancer in an individual is capable of affecting the entire family system, and its elements. The more or less adjusted and adapted members react will have a positive or negative effect on the patient. The negative impact on the family system is associated with the crisis that might arise when cancer is diagnosed. This corresponds to a situation in which the adaptation of the internal or external balance of a system is disturbed, or of an individual, and triggers a set of structural, psychological, economic and social changes, at a family and individual level $[6,8,9]$. According to Lewis [10], families of patients with cancer, experience the same requirements and challenges as patients. The way families adapt and cope with one's illness has a major impact on the physical and psychosocial well-being of their members, as well as on the clinical course of the disease itself [11].

As mentioned above, the scientific literature has increasingly viewed family members as 'co-sufferers' in the fight against cancer [12], although many processes are still unknown through which cancer can affect the family $[2,12]$. The most recent research, is focused predominantly on the impact of child cancer on their parents [13-18], on the impact of parental cancer on children and adolescents [19-26] and, still overwhelmingly, in the patients' spouses [27-32].

The psychosocial impact of parental cancer on offspring has been the subject of considerable research. As Lewis [33,34] points out, when cancer appears in the parental subsystem, it is crucial to note how members of the filial subsystem are affected. The most relevant studies, since the 1990s, were carried out on samples of children and/ or adolescents, and little relevance was given to offspring in adult- 
Advances in Mental Health Studies

hood [1,35]. Still, the work by Mosher and Weiss [36], only referring to research with this population, should be highlighted.

In a literature review, Phillips [24] examined the experiences of parents diagnosed with advanced cancer and their adolescent children. The results revealed that adolescents living with a parent with advanced cancer showed significantly higher levels of distress, anxiety, and depression than their peers. Moreover, a recent systematic review with adolescents and young adult offspring of parents with cancer concluded that they showed higher levels of anxiety, depression, and stress [26], when compared with samples without parental cancer. Nevertheless, according to the meta-analysis by Hodges, Humphris, and Macfarlane [37] on psychological distress in the relatives of cancer patients, most studies do not address adult offspring. Of the 21 studies analyzed, in 17, participants were exclusively spouses, and in the remaining 4 studies, the overwhelming majority included spouses with adult children (and other family caregivers such as mothers, sisters, siblings, nephews, etc.), representing less than $5 \%$ of the sample. Even so, it is well known that the provision of informal family care in oncology, is assumed by children, especially females, comprising an extremely vulnerable population, according to several authors [38]. In the case of daughters, and depending on the type of cancer, they are simultaneously confronted with two stressors: the parental disease and the fears inherent to their own vulnerability [39]. In this context, Baider, Ever-Hadani, and Kaplan De-Nour [40] conducted a study with a sample of 230 healthy women using the Brief Symptom Inventory (BSI) and the Impact of Event Scale (IES), relating them to the history of breast cancer in the family (in the mother or sister). Considering the latter, the authors divided the sample into three groups: women with maternal cancer, women with fraternal cancer, and women with maternal and fraternal cancer. The results showed that higher distress, and the intrusion dimension of traumatic stress, were both prevalent in all groups, especially in the latter. According to the authors, these data highlight the importance of genetic counseling and informational support to women with breast cancer in the family. Furthermore, in the abovementioned systematic review by Walc-

www.avidscience.com 
Advances in Mental Health Studies

zak et al. [26], the authors found that higher distress was associated with higher levels of posttraumatic stress disorder (PTSD) symptoms measured by the IES, in adolescents dealing with parental cancer.

Despite the volume of research with caregiver spouses, some studies also included children (small children, adolescents and adults) as participants. Lowenstein and Gilbar [41] analyzed the perception of burden among caregivers of elderly people with cancer. Although most participants were spouses, the authors also included children in adulthood; the spouses were defined as the primary caregivers, and the children as secondary caregivers. The authors found that the spouses and children reported emotional problems of the same magnitude and were even higher than those of the patients. It is interesting to note that, in this research, adult children (25-56 years of age) did not live with their parents. More recently, a cross-sectional study conducted by Rainville, Dumont, Simard, and Savard [42] that analyzed the experience of adolescents living with a parent with advanced cancer, found higher psychological distress, compared with the general population, especially if the children were older. Matthews and colleagues [3] studied the impact of cancer among spouses, middleaged adult children, and other family members (i.e., mothers, fathers, siblings, etc.). The sample also included patient friends. Although limited, an important contribution of this quantitative study was that caregivers presented higher levels in all measures of physical and emotional distress (i.e., uncertainty about the future and fear of recurrence) than patients themselves. In addition, the average outcome of caregivers, in terms of pessimistic expectations, was also significantly higher than that of patients. The results of Matthews and colleagues [3] are similar to those showed by Bowman, Rose, and Deimling [43]. These authors found that the relatives of cancer patients, both spouses and adult children, assessed the cancer experience as more stressful than patients, during diagnosis, treatment and remission. This assessment remained for years after the completion of treatment. In this study, family members were described as a single group, aged between 29 and 86 years old, although adult children and spouses were known to have different responsibilities, obligations and needs regarding car- 
Advances in Mental Health Studies

egiving [44]. In the same line of research, Boyer and colleagues [45] explored distress and PTSD symptoms among daughters (15-71 years of age) of breast cancer patients (40-95 years of age). In this study, daughters (who were mostly middle-aged and married), reported visiting the mother once a week, and close to $40 \%$ reported little or no involvement in care. Still, the vast majority of daughters (92\%) had thoughts about diagnosing stressors, and $13 \%$ had symptoms consistent with PTSD. Cohen and Pollack [46] expanded the study of Boyer and colleagues [45], adding immunological measures. Daughters (2440 years of age) were assessed in blood (plasma cortisol), urinary and hormonal parameters. The results of this study revealed that daughters whose mothers had higher levels of distress, reported greater impairment of the immune system. Daughters' distress was also associated with their perceived overload in caregiving, i.e. the daughters who were most frequently with their mothers (once in 15 days or once a week) reported greater psychological distress and burden than the daughters who were with the mothers in periods over 15 days.

As reviewed, spouses and other family members, including children, are key elements in the family and social support system for the cancer patient, evidencing that the majority handles well the role of caregiver. However, as noted by Pitceathly and Maguire [47], an important minority shows high levels of distress, developing affective disorders. Caregiver gender also appears to be a particularly important variable in caregiver studies, since the most vulnerable appears to be females, especially women with a history of prior psychological morbidity, who tend to present a more negative perception of the impact of the disease on the family life [48]. The distress in the caregiver also presents an association with the evolution of the disease for palliative care [49-53]. In the case of caregivers, the lack of support networks [51,54-57] and the existence of relational difficulties with the patient are also considered risk factors [58-61].

Considering the literature reviewed, the present chapter aims to describe and reflect on the levels of depression, anxiety, and stress of adult offspring of cancer patients, when using the DASS-21 (Depres-

www.avidscience.com 
Advances in Mental Health Studies

sion, Anxiety and Stress Scales), to analyze gender differences in psychological morbidity, as well as the association between psychological morbidity and traumatic symptomatology.

\section{Method}

\section{Participants and Procedures}

The sample consisted of 214 adult children of patients undergoing chemotherapy. The sociodemographic and clinical data collected about parents, was completed by their adult children. Of these adult children, $74 \%$ were women, with a mean age of 33.1 years $(\mathrm{SD}=9.1$; range $=18-61$ years); $47 \%$ had a partner; and $63 \%$ had less than high school education level. Concerning clinical information, $60 \%$ registered the disease duration of the parent as less than one year, $69 \%$ reported that the parent was on chemotherapy for less than one year, and only $39 \%$ provided care for more than a year. Only $21 \%$ of adult children perceived the parent in treatment as completely reliant on their caregiving. Considering the parents, $57 \%$ were female, with an average age of 62.1 years $(\mathrm{SD}=9.2$; range $=42-85$ years), and $78 \%$ were married. Regarding the type of cancer, $60 \%$ of parents had cancer of the digestive system, $21 \%$ of the reproductive system, $7 \%$ of the respiratory system and $12 \%$ in other areas.

This was a cross-sectional study approved by the Ethics Committees of three general hospitals in northern Portugal. Participants were adult children who, during the period of data collection, accompanied the parent diagnosed with cancer to chemotherapy. This was a convenience sample with voluntary participation. Inclusion criteria required that participants be age $\geq 18$ years, have a parent (or both) in chemotherapy, accompany the parent to the hospital for treatment (minimum criterion for defining the adult offspring as a "caregiver"), and not suffer from oncological, psychiatric, or neurological disease. All participants were invited to participate in the study, informed about its purpose and were assured of anonymity and confidentiality, signing an informed consent. 
Advances in Mental Health Studies

\section{Measures}

Depression, Anxiety and Stress Scales. The Portuguese version of the Depression Anxiety Stress Scales (DASS-21; Lovibond \& Lovibond, [62]; Pais-Ribeiro, Honrado, \& Leal, [63]) was used. This is a 21item questionnaire that includes three subscales: depression, anxiety, and stress. The DASS-21 employs a 4-point scale (0-3), with higher scores indicating greater negative affective state. This scale has specific qualities: is short, easy to apply in clinical and non-clinical settings and can be used for the simultaneous evaluation of depression, anxiety, and stress in adolescents and adults (> 17 years old). The three subscales of the DASS-21 can be considered consistent with the tripartite model of Clark and Watson [64], since depression is characterized by reduced self-esteem, reduced incentive and hopelessness; anxiety by physiological hyperstimulation; and stress from persistent tension, irritability, and a low threshold to frustration. In this sample, Cronbach's alphas were appropriate: total scale "distress" $(\alpha=0.94)$, depression $(\alpha=0.89)$, anxiety ( $\alpha=0.82)$, and stress $(\alpha=0.87)$. In addition, the scale allows an evaluation of the severity of distress symptoms by calculating the percentages of responses related to the severity of affective-emotional states, with the cutoff points suggested by Lovibond and Lovibond [62]. The study of Crawford and Henry [65] in the United Kingdom refers to its use, and in Portugal, Apóstolo, Mendes, and Rodrigues [66], and Apóstolo, Ventura, Caetano, and Costa [67] used the same methodology.

Impact of Event Scale-Revised. The 22-item Portuguese version of the Impact of Event Scale-Revised (IES-R; Weiss \& Marmar, [68]; Pereira \& Teixeira, [69] was used. This is a measure of current subjective distress for a specific traumatic event. Respondents are asked to rate on a 5-point scale (0-4) how distressing symptoms of avoidance, hyperarousal, and intrusion have been in the past 7 days. The IES-R has already been used in cancer patients [70]. Higher scores indicate higher number of traumatic stress symptoms. In this sample, Cron-

www.avidscience.com 
Advances in Mental Health Studies

bach's alphas were 0.93 for hyperarousal, 0.74 for intrusion, 0.70 for avoidance, and 0.93 for the total scale.

\section{Data Analysis}

For the statistical analysis of the data, the IBM SPSS Statistics, version 22 was used. Descriptive statistics were performed for the sociodemographic variables, followed by Pearson coefficient analysis of the variables under study (distress and PTSD symptoms). T-tests for independent samples were performed to analyze gender differences.

\section{Results}

Considering the severity of psychological morbidity, 6-60\% of the participants showed 'normal' or 'mild' levels of stress, anxiety, or depression; 15-26\% 'moderate' levels; and 4-12\% 'severe' or 'extremely severe' levels of stress, anxiety, or depression (Table 1).

Table 1: Severity of psychological morbidity in adult offspring caregivers.

\begin{tabular}{|l|c|c|c|c|c|}
\hline & Normal & Mild & Moderate & Severe & Extremely severe \\
\hline Depression $^{1}$ & $(0-9)^{*}$ & $(10-13)^{*}$ & $(14-20)^{*}$ & $(21-27)^{*}$ & $(28+)^{*}$ \\
& --- & --- & --- & --- & --- \\
& $60.3 \%$ & $13.6 \%$ & $15 \%$ & $5.1 \%$ & $6.1 \%$ \\
\hline Anxiety $^{1}$ & $(0-7)^{*}$ & $(8-9)^{*}$ & $(10-14)^{*}$ & $(15-19)^{*}$ & $(20+)^{*}$ \\
& --- & --- & --- & --- & --- \\
& $55.1 \%$ & $5.6 \%$ & $25.7 \%$ & $3.7 \%$ & $9.8 \%$ \\
\hline Stress $^{1}$ & $(0-14)^{*}$ & $(15-18)^{*}$ & $(19-25)^{*}$ & $(26-33)^{*}$ & $(34+)^{*}$ \\
& --- & --- & --- & --- & --- \\
& $47.7 \%$ & $15.9 \%$ & $18.7 \%$ & $11.7 \%$ & $6.1 \%$ \\
\hline
\end{tabular}

Note. $\mathrm{N}=214 .{ }^{1}$ DASS-21. ${ }^{\star}$ Reference values reported by Lovibond and Lovibond [62], and used in Portuguese samples [66,67]. 
When analyzing gender differences (Table 2), statistically significant values were found for anxiety, stress, and total distress. Thus, women showed higher indicators of anxiety, stress, and total distress than men. There were no significant differences between women and men in terms of depression.

Table 2: Gender differences in the variables of depression, anxiety and stress in the adult offspring caregivers.

\begin{tabular}{|l|c|c|c|}
\hline & Women & Men & $t(212)$ \\
& $(\mathrm{n}=158)$ & $(\mathrm{n}=56)$ & \\
\hline Depression $^{1}$ & $10.27(9.97)$ & $7.71(6.01)$ & -1.810 \\
\hline Anxiety $^{1}$ & $8.69(8.35)$ & $5.75(5.77)$ & $-2.439 * *$ \\
\hline Stress $^{1}$ & $17.18(9.25)$ & $14.32(8.82)$ & $-2.016^{*}$ \\
\hline Distress (total) $^{1}$ & $36.16(25.04)$ & $27.78(16.90)$ & $-2.321^{*}$ \\
\hline
\end{tabular}

Note. $\mathrm{N}=214 .{ }^{*} \mathrm{p}<0.05 .{ }^{* *} \mathrm{p}<0.01 .{ }^{1} \mathrm{DASS}-21$.

The correlation analysis showed statistically significant values (Table 3) with strong positive correlations ( $\mathrm{r}$-values between 0.426 and $0.898, \mathrm{p}<0.001)$ among all the variables from the DASS-21 and the IES-R. 
Advances in Mental Health Studies

Table 3: Pearson correlations between DASS-21 and IES-R.

\begin{tabular}{|c|c|c|c|c|c|c|c|c|}
\hline & 1 & 2 & 3 & 4 & 5 & 6 & 7 & 8 \\
\hline 1. Depression ${ }^{1}$ & - & $730^{* * *}$ & $.668^{* * *}$ & $.898^{* * * *}$ & $.461 * * *$ & $.579 * * *$ & $.561^{* * *}$ & $.609^{* * *}$ \\
\hline 2. Anxiety ${ }^{1}$ & & - & $.701 * * *$ & $.896 * * *$ & $.489 * * *$ & $.514 * * *$ & $.604 * * *$ & $.613^{* * *}$ \\
\hline 3. Stress $^{1}$ & & & - & $.889^{* * *}$ & $.426 * * *$ & $.451^{* * *}$ & $.576^{* * *}$ & $.556^{* * *}$ \\
\hline 4. Distress (total) 1 & & & & - & $.511 * * *$ & $.576^{* * *}$ & $.648^{* * *}$ & $.662 * * *$ \\
\hline 5. Avoidance ${ }^{2}$ & & & & & - & $.666^{* * * *}$ & $.688^{* * *}$ & $.884^{* * *}$ \\
\hline 6. Intrusion ${ }^{2}$ & & & & & & - & $.628^{* * *}$ & $.864 * * *$ \\
\hline 7. Hyperarousal ${ }^{2}$ & & & & & & & - & $.890^{* * * *}$ \\
\hline $\begin{array}{l}\text { 8. PTSD symptoms } \\
\text { (total) }{ }^{2}\end{array}$ & & & & & & & & - \\
\hline
\end{tabular}

Note. $\mathrm{N}=214 .{ }^{* *} \mathrm{p}<0.001 .{ }^{1}$ DASS- $21 ;{ }^{2}$ IES-R.

\section{Discussion and Conclusions}

The diagnosis of cancer continues to represent a huge impact both on the life of the patients, but also on the life of the family member and/or caregiver [71], with almost $30 \%$ of families showing clinically significant levels of psychological distress requiring professional intervention [72]. Although a recent systematic review with adolescent and young adults facing parental cancer found that they showed higher levels of anxiety, depression, and stress [26], the present study found normal to moderate levels of depression, anxiety, and stress in adults who cared for their parents. This finding suggests that most adult offspring are able to meet the many challenges associated with caring of an adult with cancer, without experiencing severe psychological debilitations. These results are in accordance with those of Rodrigue and Hoffmann [73]. However, 11\% showed worrying levels (severe or extremely severe) of depressive symptoms, $14 \%$ of anxiety symptoms and $18 \%$ of stress, being consistent with previous research on caregivers of chronic cancer patients [74,75]. 
Advances in Mental Health Studies

Results also showed that women reported higher levels of anxiety, stress, and total distress, than men. These results are in accordance with existing literature, not only in 'general' cancer caregiving [12,48], but also in adolescent and young adult offspring's cancer caregiving $[76,77]$. Also a study conducted with spouses and offspring caregivers of cancer survivors found that women assessed their caregiving experience as stressful and, the daughters, in particular, reported the highest levels of stress [78]. Sons, in turn, showed the lowest levels of caregiving stress [78]. These gender differences may be explained by the multiple demands of the several roles that adult daughters have to manage, in addition to their caregiving role. In fact, these women have been called the "sandwich generation", because they often have to balance employment outside their home with family and children, household tasks, social life, as well as caring for the parent with cancer [1]. Thus, it makes intuitive sense to provide psychological interventions focused on the distress to adult daughters of oncological patients.

Finally, the results showed that higher levels of psychological morbidity were strongly associated with PTSD symptoms, confirming previous studies in adolescent children of parents with cancer [26]. A diagnosis of parental cancer is a life-threatening event that may be considered traumatic and contribute to the development of PTSD symptoms. The offspring of parents with cancer, not only the suffering of a loved one, but also have to cope with their own vulnerability (e.g., potential genetic risk) and mortality, which may lead to the development of anxiety, depression, and stress symptoms $[1,79,80]$.

This study's main limitations are the higher prevalence of women in the sample (almost 75\%); the fact that the reference values reported by Lovibond and Lovibond [62], and used in Portugal by Apóstolo and colleagues [66,67] just for classification purposes, may be out of date for the Portuguese cancer caregiving reality; and the cross-sectional design of the study. Therefore, future studies should include longitudinal designs and address how distress and traumatic symptomatology change over time in adult offspring of oncological patients.

www.avidscience.com 
Advances in Mental Health Studies

The findings of this study suggest that the offspring caregivers of cancer patients need intervention programs designed to help them deal with distress and traumatic symptoms. Therefore, intervention should provide emotional and instrumental support to minimize and help them adapt to the situation. According to the results, it would be also important that the intervention be offered in the context of the dyad patient-caregiver. Particular attention should be paid to women caregivers, since they showed higher levels of distress, particularly anxiety and stress.

\section{Acknowledgements}

This study was conducted at Psychology Research Centre (PSI/01662), University of Minho, and supported by the Portuguese Foundation for Science and Technology and the Portuguese Ministry of Science, Technology and Higher Education through national funds, and co-financed by FEDER through COMPETE2020 under the PT2020 Partnership Agreement (POCI-01-0145-FEDER-007653).

\section{References}

1. Mosher CE, Danoff-Burg S. Psychosocial impact of parental cancer in adulthood: A conceptual and empirical review. Clinical Psychology Review. 2005; 25: 365-382.

2. Thomas C, Morris SM. Informal carers in cancer contexts. European Journal of Cancer Care. 2002; 11: 178-182.

3. Matthews BA, Baker F, Spillers R. Family caregivers and indicators of cancer-related distress. Psychology, Health \& Medicine. 2003; 8: 45-56.

4. Edwards B, Clarke V. The psychological impact of a cancer diagnosis on families: The influence of family functioning and patients' illness characteristics on depression and anxiety. Psycho-Oncology. 2004; 13: 562-576. 
Advances in Mental Health Studies

5. Given CW, Stommel M, Given B, Osuch J, Kurtz ME, et al. The influence of cancer patients' symptoms and functional states on patients' depression and family caregivers' reaction and depression. Health Psychology. 1993; 12: 277-285.

6. Alarcão M. (Des)equilíbrios familiares: Uma visão sistémica. Family (in)balances: A systemic view, 3rd edn. Portugal: Quarteto. 2006.

7. Bloom JR. Social support of the cancer patient and the role of the family. In: L Baider, CL Cooper, A K De-Nour, editors. Cancer and the family, $2^{\text {nd }}$ edn. Chichester: John Wiley \& Sons. 1996; 53-70.

8. Duhamel F. The practice of family nursing care: Still a challenge!. Canadian Journal of Nursing Research. 1995; 27: 7-11.

9. Rolland JS. Anticipatory loss: A family systems developmental framework. Family Process. 1990; 29: 229-244.

10. Lewis FM. The family's stuck points in adjusting to cancer. In: JC Holland, WS Breitbart, PB Jacobsen, MS Lederberg, MJ Loscalzo, editors. Psycho-oncology $2^{\text {nd }}$ edn. Oxford: Oxford University Press. 2010; 511-515.

11. Tansella CZ. Psychosocial factors and chronic illness in childhood. European Psychiatry. 1995; 10: 297-305.

12. Matthews BA. Role and gender differences in cancer-related distress: A comparison of survivor and caregiver self-reports. Oncology Nursing Forum. 2003; 30: 493-499.

13. Gudmundsdottir E, Schirren M, Boman KK. Psychological resilience and long-term distress in Swedish and Icelandic parents' adjustment to childhood cancer. Acta Oncologica. 2011; 50: 373-380.

14. Hovén E, Grönqvist H, Pöder U, von Essen L, Lindahl Norberg A. Impact of a child's cancer disease on parents' eve- 
Advances in Mental Health Studies

ryday life: A longitudinal study from Sweden. Acta Oncologica. 2017; 56: 93-100.

15. Ljungman L, Cernvall M, Grönqvist H, Ljótsson B, Ljungman $G$, et al. Long-term positive and negative psychological late effects for parents of childhood cancer survivors: A systematic review. PLoS one. 2014; 9: e103340.

16. Rosenberg AR, Dussel V, Kang T, Geyer JR, Gerhardt CA, et al. Psychological distress in parents of children with advanced cancer. JAMA Pediatrics. 2013; 167: 537-543.

17. Silva FM, Jacob E, Nascimento LC. Impact of childhood cancer on parents' relationships: An integrative review. Journal of Nursing Scholarship. 2010; 42: 250-261.

18. Wikman A, Hovén E, Cernvall M, Ljungman G, Ljungman $\mathrm{L}$, et al. Parents of children diagnosed with cancer: Work situation and sick leave, a five-year post end-of-treatment or a child's death follow-up study. Acta Oncologica. 2016; 55: 1152-1157.

19. Huang X, O'connor M, Lee S. School-aged and adolescent children's experience when a parent has non-terminal cancer: A systematic review and meta-synthesis of qualitative studies. Psycho-Oncology. 2014; 23: 493-506.

20. Huizinga GA, Visser A, Zelders-Steyn YE, Teule JA, Reijneveld SA, et al. Psychological impact of having a parent with cancer. European Journal of Cancer. 2011; 47: S239-S246.

21. Kennedy VL, Lloyd-Williams M. How children cope when a parent has advanced cancer. Psycho-Oncology. 2009; 18: 886-892.

22. Krattenmacher T, Kühne F, Ernst J, Bergelt C, Romer G, et al. Parental cancer: Factors associated with children's psychosocial adjustment - a systematic review. Journal of Psychosomatic Research. 2012; 72: 344-356. 
Advances in Mental Health Studies

23. Morris JN, Martini A, Preen D. The well-being of children impacted by a parent with cancer: An integrative review. Supportive Care in Cancer. 2016; 24: 3235-3251.

24. Phillips F. Adolescents living with a parent with advanced cancer: A review of the literature. Psycho-Oncology. 2014; 23: 1323-1339.

25. Shah BK, Armaly J, Swieter E. Impact of parental cancer on children. Anticancer Research. 2017; 37: 4025-4028.

26. Walczak A, McDonald F, Patterson P, Dobinson K, Allison K. How does parental cancer affect adolescent and young adult offspring? A systematic review. International Journal of Nursing Studies. 2018; 77: 54-80.

27. Badr H, Herbert K, Reckson B, Rainey H, Sallam A, et al. Unmet needs and relationship challenges of head and neck cancer patients and their spouses. Journal of Psychosocial Oncology. 2016; 34: 336-346.

28. Drabe N, Klaghofer R, Weidt S, Zwahlen D, Büchi S, et al. Mutual associations between patients' and partners' depression and quality of life with respect to relationship quality, physical complaints, and sense of coherence in couples coping with cancer. Psycho-Oncology. 2015; 24: 442-450.

29. Morgan MA, Small BJ, Donovan KA, Overcash J, McMillan S. Cancer patients with pain: The spouse/partner relationship and quality of life. Cancer Nursing. 2011; 34: 13-23.

30. Moser MT, Künzler A, Nussbeck F, Bargetzi M, Znoj HJ. Higher emotional distress in female partners of cancer patients: Prevalence and patient-partner interdependencies in a 3-year cohort. Psycho-Oncology. 2013; 22: 2693-2701.

31. Wells-Di Gregorio S, Carpenter KM, Dorfman CS, Yang HC, Simonelli LE, et al. Impact of breast cancer recurrence and cancer-specific stress on spouse health and immune 
Advances in Mental Health Studies

function. Brain, Behavior, and Immunity. 2012; 26: 228-233.

32. Wu LM, Mohamed NE, Winkel G, Diefenbach MA. Patient and spouse illness beliefs and quality of life in prostate cancer patients. Psychology \& Health. 2013; 28: 355-368.

33. Lewis FM. Family-focused oncology nursing research. Oncology Nursing Forum. 2004; 31: 288-292.

34. Lewis FM, Hammond MA. The father's, mother's, and adolescent's functioning with breast cancer. Family Relations. 1996; 45: 456-465.

35. Lekeisha S, Wellisch D, Youngmee K, Spillers R. Psychological characteristics of adult daughters of breast cancer patients: Comparison of clinic and community caregivers samples. Journal of Psychosocial Oncology. 2015; 33: 561575 .

36. Mosher CE, Weiss TR. Psychosocial research and practice with adult children of cancer patients. In: JC Holland, WS Breitbart, PB Jacobsen, MS Lederberg, MJ Loscalzo, editors. Psycho-oncology, $2^{\text {nd }}$ edn. Oxford: Oxford University Press. 2010; 532- 536.

37. Hodges LJ, Humphris GM, Macfarlane G. A meta-analytical investigation of the relationship between the psychological distress of cancer patients and their carers. Social Science \& Medicine. 2005; 60: 1-12.

38. Wellisch DK, Hoffman A, Gritz E. Psychological concerns and care of daughters of breast cancer patients. In: L Baider, CL Cooper, AK De-Nour, editor. Cancer and the family. New York: John Wiley \& Sons. 1996; 289-304.

39. Raveis VH, Pretter S. Existential plight of adult daughters following their mother's breast cancer diagnosis. PsychoOncology. 2005; 14: 49-60. 
Advances in Mental Health Studies

40. Baider L, Ever-Hadani P, Kaplan De-Nour A. Psychological distress in healthy women with familial breast cancer: Like mother, like daughter? International Journal of Psychiatry in Medicine. 1999; 29: 411-420.

41. Lowenstein A, Gilbar O. The perception of caregiving burden on the part of elderly cancer patients, spouses, and adult children. Families, System, and Health. 2000; 18: 337-346.

42. Rainville F, Dumont S, Simard S, Savard M. Psychological distress among adolescents living with a parent with advanced cancer. Journal of Psychosocial Oncology. 2012; 30: 519-534.

43. Bowman KF, Rose JH, Deimling GT. Appraisal of the cancer experience by family members and survivors in long-term survivorship. Psycho-Oncology. 2006; 15: 834-845.

44. Bakas T, Lewis RR, Parsons E. Caregiving tasks among family caregivers of patients with lung cancer. Oncology Nursing Forum. 2001; 28: 847-854.

45. Boyer BA, Bubel D, Jacobs SR, Knolls ML, Harwell VD, et al. Posttraumatic stress in women with breast cancer and their daughters. American Journal of Family Therapy. 2002; 30: 323-338.

46. Cohen M, Pollack S. Mothers with breast cancer and their adult daughters: The relationship between mothers' reaction to breast cancer and their daughters' emotional and neuroimmune status. Psychosomatic Medicine. 2005; 67: 64-71.

47. Pitceathly C, Maguire P. The psychological impact of cancer on patients' partners and other key relatives: A review. European Journal of Cancer. 2003; 39: 1517-1524.

48. Loscalzo MJ, Kim Y, Clark KL. Gender and caregiving. In: JC Holland, WS Breitbart, PB Jacobsen, MS Lederberg, MJ Loscalzo, editors. Psycho-oncology, 2nd edn. Oxford: Ox- 
Advances in Mental Health Studies

ford University Press. 2010; 522-526.

49. Aoun SM, Kristjanson LJ, Currow DC, Hudson PL. Caregiving for the terminally ill: At what cost? Palliative Medicine. 2005; 19: 551-555.

50. Astudillo W, Mendinueta C, Granja P. Cómo apoyar al cuidador de un enfermo en el final de la vida [How to support the caregiver of a sick person at the end of life]. Psicooncología. 2008; 5: 359-381.

51. Payne S, Smith P, Dean S. Identifying the concerns of informal carers in palliative care. Palliative Medicine. 1999; 13: 37-44.

52. Poole K, Froggatt K. Loss of weight and loss of appetite in advanced cancer: A problem for the patient, the carer, or the health professional? Palliative Medicine. 2002; 16: 499-506.

53. Rossi Ferrario S, Cardillo V, Vicario F, Balzarini E, Zotti AM. Advanced cancer at home: Caregiving and bereavement. Palliative Medicine. 2004; 18: 129-136.

54. Black K, Lobo M. A conceptual review of family resilience factors. Journal of Family Nursing. 2008; 14: 33-55.

55. Nijboer C, Tempelaar R, Sanderman R, Triemstra M, Spruijt $\mathrm{RJ}$, et al. Cancer and caregiving: The impact on the caregiver's health. Psycho-Oncology. 1998; 7: 3-13.

56. Payne S, Ellis-Hill C. Being a carer. In S. Payne \& C. EllisHill (Eds.), Chronic and terminal illness: New perspectives on caring and carers. New York: Oxford University Press. 2001; 1-21.

57. Zabalegui A, Bover A, Rodriquez E, Cabrera E, Diaz M, et al. Informal caregiving: Perceived needs. Nursing Science Quarterly. 2008; 21: 166-172. 
Advances in Mental Health Studies

58. Bascom PB, Tolle SW. Care of the family when the patient is dying. The Western Journal of Medicine. 1995; 163: 292296.

59. Braun M, Mikulincer M, Rydall A, Walsh A, Rodin G. Hidden morbidity in cancer: Spouse caregivers. Journal of Clinical Oncology. 2007; 25: 4829-4834.

60. Kuscu MK, Dural U, Onen P, Yaşa Y, Yayla M, et al. The association between individual attachment patterns, the perceived social support, and the psychological well-being of Turkish informal caregivers. Psycho-Oncology. 2009; 18: 927-935.

61. Miller RD, Walsh TD. Psychosocial aspects of palliative care in advanced cancer. Journal of Pain and Symptom Management. 1991; 6: 24-29.

62. Lovibond P, Lovibond S. The structure of negative emotional states: Comparison of the Depression Anxiety Stress Scales (DASS) with the Beck Depression and Anxiety Inventories. Behaviour Research and Therapy. 1995; 33: 335-343.

63. Pais-Ribeiro JL, Honrado A, Leal I. Contribuição para o estudo da adaptação portuguesa das escalas de ansiedade, depressão e stress (EADS) de 21 itens de Lovibond e Lovibond [Contribution to the study of the Portuguese adaptation of the anxiety, depression and stress scales (DASS) of 21 items of Lovibond and Lovibond]. Psicologia, Saúde \& Doenças. 2004; 5: 229-239.

64. Clark LA, Watson D. Tripartite model of anxiety and depression: Psychometric evidence and taxonomic implications. Journal of Abnormal Psychology. 1991; 100: 316- 336.

65. Crawford JR, Henry JD. The Depression Anxiety Stress Scales (DASS): Normative data and latent structure in a 
Advances in Mental Health Studies

large non-clinical sample. British Journal of Clinical Psychology. 2003; 42: 111-131.

66. Apóstolo JL, Mendes AC, Rodrigues MA. Propriedades psicométricas da Escala de Depressão, Ansiedade e Stresse (DASS-21), numa amostra não clínica [Psychometric properties of the Depression, Anxiety and Stress Scale (DASS$21)$ in a non-clinical sample]. Revista Investigação em Enfermagem. 2007; 15: 66-76.

67. Apóstolo JA, Ventura A, Caetano C, Costa S. Depressão, ansiedade e stresse em utentes de cuidados de saúde primários [Depression, anxiety and stress in primary care users]. Revista Referência. 2008; 2: 45-49.

68. Weiss DS, Marmar C. The Impact of Event Scale-Revised. In: JP Wilson, TM Keane, editors. Assessing psychological trauma and PTSD: A practitioner's handbook. New York: Guilford Press. 1997; 399-411.

69. Pereira MG, Teixeira RJ. Poster abstract - Portuguese validation of the Impact of Event Scale-Revised (IES-R) in adult children of cancer patients. Psycho-Oncology. 2001; 20: 105-300.

70. O'Connor M, Christensen S, Jensen AB, Moller S, Zachariae R. How traumatic is breast cancer? Post-traumatic stress symptoms (PTSS) and risk factors for severe PTSS at 3 and 15 months after surgery in a nationwide cohort of Danish women treated for primary breast cancer. British Journal of Cancer. 2010; 104: 419-426.

71. Kurtz ME, Kurtz JC, Given CW, Given BA. Relationship of caregiver reactions and depression to cancer patients' symptoms, functional states and depression - A longitudinal view. Social Science and Medicine. 1995; 40: 837-846.

72. Sales E, Schulz R, Biegel D. Predictors of strain in families of cancer patients: A review of the literature. Journal of Psychosocial Oncology. 1992; 10: 1-26. 
Advances in Mental Health Studies

73. Rodrigue JR, Hoffmann RG. Caregivers of adults with cancer: Multidimensional correlates of psychological distress. Journal of Clinical Psychology in Medical Settings. 1994; 1: 231-244.

74. Ell K, Nishimoto R, Mantell J, Hamovitch M. Longitudinal analysis of psychological adaptation among family members of patients with cancer. Journal of Psychosomatic Research. 1988; 32: 429-438.

75. Keitel MA, Zevon MA, Rounds JB, Petrelli NJ, Karakousis C. Spouse adjustment to cancer surgery: Distress and coping responses. Journal of Surgical Oncology. 1990; 43: 148153.

76. Kazak AE, Christakis D, Alderfer M, Coiro MJ. Young adolescent cancer survivors and their parents: Adjustment, learning problems, and gender. Journal of Family Psychology. 1994; 8: 74-84.

77. McDonald FEJ, Patterson P, White KJ, Butow PN, Costa DSJ, et al. Correlates of unmet needs and psychological distress in adolescent and young adults who have a parent diagnosed with cancer. Psycho-Oncology. 2016; 25: 447-454.

78. Kim Y, Baker F, Spillers RL. Cancer caregivers' quality of life: Effects of gender, relationship, and appraisal. Journal of Pain and Symptom Management. 2007; 34: 294-304.

79. Gallagher J, Parle M, Cairns D. Appraisal and psychological distress six months after diagnosis of breast cancer. British Journal of Health Psychology. 2002; 7: 365-376.

80. Sumalla EC, Ochoa C, Blanco I. Posttraumatic growth in cancer: Reality or illusion? Clinical Psychology Review. 2009; 29: 24-33. 